Article

\title{
Open Access Routes Dichotomy and Opportunities: Consolidation, Analysis and Trends at the Spanish National Research Council
}

\author{
Mercedes Baquero-Arribas, Luis Dorado $\mathbb{D}$ and Isabel Bernal * \\ Spanish National Research Council (CSIC), Unit of Information Resources for Research, C/Joaquin Costa 22, \\ 28002 Madrid, Spain \\ * Correspondence: isabel.bernal@bib.csic.es
}

Received: 30 April 2019; Accepted: 28 June 2019; Published: 3 July 2019

\begin{abstract}
This article gives a comprehensive overview of recent Spanish National Research Council (CSIC) publications available in Open Access. With a focus on research articles from the last decade (2008-2018), this work aims to fill the gap in previous studies about publishing trends and impact monitoring of publications by researchers from the Spanish National Research Council. Evolution and main trends of Green and Gold Open Access routes at CSIC are addressed through a close insight into DIGITAL.CSIC repository and institutional Open Access Publishing Support Programme. The article draws on major conclusions at a time when an institutional Open Access mandate has just entered into force. The article also relates findings about performance of institutional Open Access Publishing Initiative and total volume of CSIC articles published in Open Access with an estimation of overall costs on article processing charges during these years. Furthermore, the data serve as a basis to make preliminary considerations as to opportunities to move from a subscription-based model to one fully aligned with Gold Open Access publishing. The data analyzed come from a variety of sources, including public information and internal records maintained by the CSIC E-resources Subscription programme, DIGITAL.CSIC and data retrieved from GesBIB, an internal, in-house development tool that integrates bibliographic information about CSIC publications as well as data from several external APIs, including Unpaywall, DOAJ and Sherpa Romeo.
\end{abstract}

Keywords: Open Access; Open Access publishing fund; APCs monitoring; scholarly publishing; Digital.Csic; transparency of costs; transformative agreements

\section{Introduction}

The Spanish National Research Council (CSIC) is the largest public institution dedicated to research in Spain and is one of the largest in Europe. According to 2017 Annual Report [1], CSIC consists of 120 institutes (67 on its own and 53 joint institutes in collaboration with 43 public universities). Total staff, distributed across institutes and central services, amounts to a bit more than 11,000, out of whom around 5000 are directly devoted to doing research, including permanent, hired researchers, fellows, and in-training researchers. Belonging to the Spanish Ministry of Science, Innovation and Universities [2], CSIC's main objective is to develop and promote research that will help bring about scientific and technological progress, and for this purpose it collaborates with a wide network of Spanish and foreign entities. The total budget in 2017 amounted to some 737 million euro and was composed of State funds, competitive research calls and European Regional Development Fund (ERDF) assistance.

CSIC research revolves around eight principal scientific-technical areas ranging from the most basic or fundamental aspects of science to the most complex technological developments, from human 
and social sciences to food science and technology, including Biology, Biomedicine, Physics, Chemistry and Materials, Natural Resources and Agriculture.

CSIC is activity-intensive when it comes to publishing productivity. According to the institutional tool GesBIB, CSIC publications (including all typologies) surpassed 143,000 between 2008 and 2018. This volume represents $14 \%$ of all Spain's scientific publications in the given period [3]. Research articles (including original articles and proceeding papers) stand as the predominant publication type and English is by large the most widely used language. Publication in books, monographs and journals that are not on Web of Science (WoS) and Scopus indexes outstands in Humanities/Social Sciences institutes.

On the whole, CSIC publications are closely aligned with impact factor journals listings. A high percentage of CSIC articles are published in Q1 titles: $66 \%$ according to Journal Citation Reports (JCR), 78\% according to CiteScore and $81 \%$ according to Scimago Journal Rank (SJR). CSIC articles in well-reputed journals such as Science and Nature account for $41 \%$ and $32 \%$ of Spanish articles in such titles, respectively.

Most CSIC publications are the result of institutional, national and international collaboration. In fact, co-authorship with national and foreign peers is over the average in Spain and this difference is all the more evident as far as international co-authorship is concerned [4]. In general terms, collaboration is more often nurtured with universities and other academic institutions as well as multisectorial entities. International collaboration is mostly sealed with researchers from other EU countries, followed by North America and Latin America. International cooperation ranks the highest in CSIC institutes devoted to Physics. Such feature is found the least in Humanities/Social Sciences institutes; however, an ascending trend has been recorded over the last years.

A WoS-based analysis of number of CSIC publications in 2018 by thematic areas sheds light on CSIC relevance in Chemistry, Biochemistry, Molecular Biology, Environmental Sciences, Physics, Genetics, Engineering, Materials Sciences and Agriculture. In fact, CSIC articles from Q1 Impact Factor (IF) journals and high citation rates abound in Physics (22\%), Natural Resources (19\%), Biology $(17 \%)$, Materials Science (15\%), Chemistry (13\%), Agricultural Sciences (10\%), Food Science (6\%) and Humanities (1\%).

Scientific recognition of CSIC publications is well documented. According to WoS data for 2008-2018, CSIC research articles accumulated a bit more than 2,171,000 citations. For its part, a recent update of Nature Index [5] places CSIC in the 50th position of world ranking that measures impact of first 500 scientific institutions.

Open Access to CSIC publications has made significant headway over the last year and this article will provide a comprehensive analysis. In total, nearly 60,000 CSIC research articles dated between 2008 and 2018 are already available in Open Access, either through publisher platform or through an Open Access repository (Figure 1). This figure is quite significant in quantitative terms and reveals constant expansion of both Open Access routes amongst institutional authors.

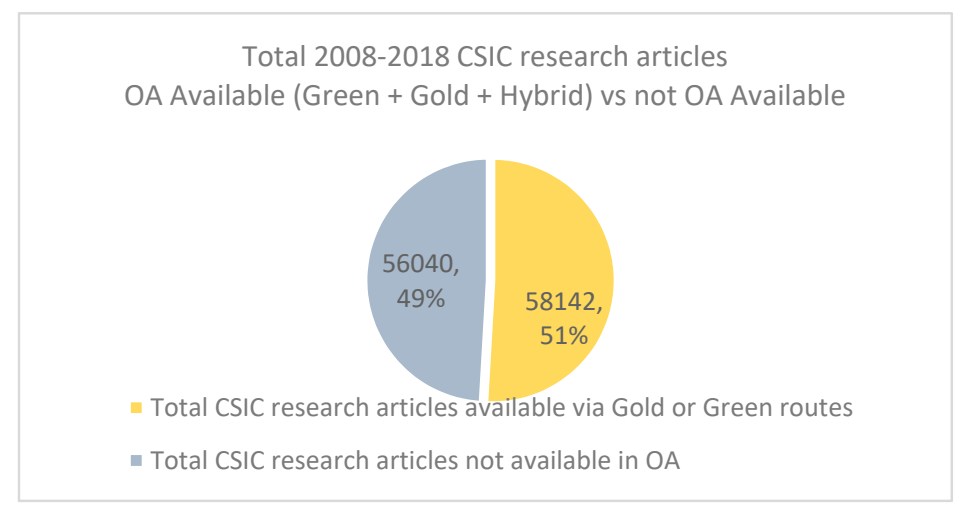

Figure 1. Percentage of Spanish National Research Council (CSIC) research articles available in Open Access (OA) as compared to total volume of CSIC research articles published in 2008-2018. 


\section{Open Access Programmes Run by CSIC Libraries Network}

\subsection{DIGITAL.CSIC: Institutional Green Route}

DIGITAL.CSIC is a direct consequence of the signing by CSIC Presidency of the Berlin Declaration in 2006, which marked CSIC official commitment to disseminating its research outputs Open Access. As a result, two institutional initiatives kicked off: on one hand, CSIC Press Department started Revistas CSIC in June 2007, a major publishing initiative; on the other hand, CSIC Unit of Information Resources for Research URICI initiated institutional repository DIGITAL.CSIC in January 2008. In April 2019 an Open Access Mandate through DIGITAL.CSIC came into force and is a major support to further consolidation of the Green Route within the institution [6].

URICI is a Central Services department that coordinates and advances knowledge management and research libraries related services to all CSIC institutes. URICI is also in charge of negotiating licensing agreements with publishers for the whole of CSIC and the sponsor behind the institutional Open Access publication Fund. In addition, DIGITAL.CSIC receives support from CSIC's Central IT Services Department in terms of systems applications and processes, storage and preservation tasks.

The repository develops through a dedicated team ("Technical Office" from now on). Content growth on DIGITAL.CSIC rests on a distributed model whereby in addition to its Technical Office, the network of CSIC research libraries plays an active role in increasing repository's collections and enabling Open Access. This Mediated Archiving Service is provided to institutional authors as a channel for them to delegate on the Technical Office or their library the deposit of their research outputs and it accounts for more than $90 \%$ of research outputs upload and the remainder results from author's self-archiving and automated bulk ingests managed by DIGITAL.CSIC Technical Office [7]. CSIC authors may make use of the Mediated Archiving Service by using a tailor-made web form or by directly sending basic metadata and their authors' manuscripts by email and the service has proved quite successful to keep a steady pace towards content increase while assuring fairly good metadata quality standards, good digital curation and timely compliance with copyright and publishers self-archiving policies.

The repository seeks to enable free availability and reuse to as much content (journal articles, conference proceedings, books and book chapters, presentations, audiovisual material, data, working papers and so on) as possible and in all instances it provides a free bibliographic database. Over the last few years, DIGITAL.CSIC has paid growing attention to offering advanced services to institutional researchers, giving support to comply with funders' Open Access mandates and promote Open Access to data and other non-traditional outputs.

Content-wise, one remarkable DIGITAL.CSIC added value concerns the mere volume of journal articles available in Open Access. In fact, with over 102,000 papers (of which more than 65,000 are accessible for free or under publisher embargo period while the remainder are metadata-only items because self-archiving is prohibited by publishers, authors have not kept a valid version for the repository, or they are print-only publications), it stands as the top research type in DIGITAL.CSIC. This significant collection of papers online is followed by far by the remainder of research outputs-about 15,000 conference contributions being the second most representative typology, followed by about 11,000 research data, of which more than $70 \%$ are Open Access, as third top typology (see Figure 2). Research data have consolidated as an important output typology on DIGITAL.CSIC over the last years and they represent a broad community of research results ranging from images to observational and experimental data, survey results, descriptions of archaeological artifacts and so on. DIGITAL.CSIC does not impose any usage license but recommends Creative Commons CC-BY 4.0 These numbers emphasize the important role that DIGITAL.CSIC plays for Open Access to CSIC scientific results and is the basis for a number of analyses in sections below. 


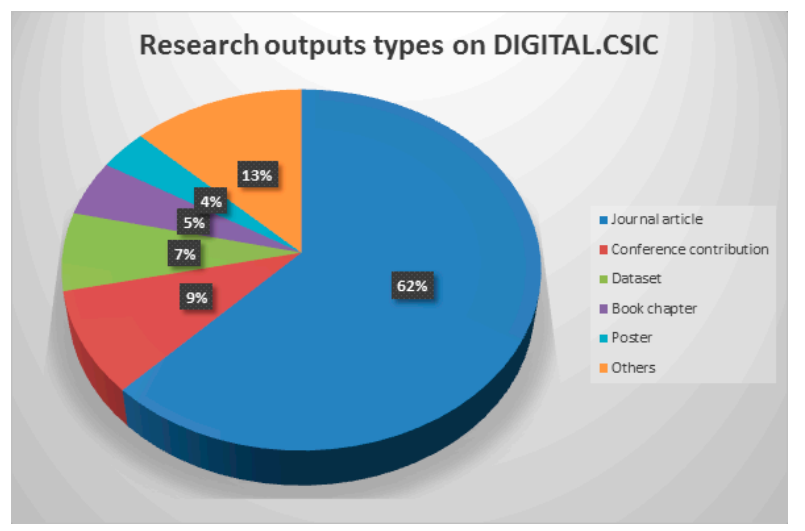

Figure 2. Distribution of contents on DIGITAL.CSIC by resource type. Source: DIGITAL.CSIC.

\subsection{DIGITAL.CSIC Roadmap towards Open Science}

In 2018, DIGITAL.CSIC turned 10 years and several landmarks were signaled during this period. With over 165,000 research outputs available at time of writing (March 2019), it is the largest institutional Open Access repository in the country and a remarkable player in advancing Open Science in Spain. By way of illustration, DIGITAL.CSIC is participating in the ongoing INEOS project [8] in partnership with Spanish Foundation of Science and Technology (FECYT) to foster usage of institutional repositories as research data platforms, implement cutting edge standards to better manage and link data with associated publications, and integrate repositories with national public researcher profiles infrastructures (CVN in Spanish acronym).

Further, DIGITAL.CSIC is actively involved in several international initiatives that call for a transformative scholarly communication system and for positioning the global network of repositories at its core. Thus, since 2010 it has been supporting COAR vision as a member organization, and since 2014 DIGITAL.CSIC has engaged in several COAR efforts to enhance interoperability amongst open infrastructures on the web and to maximize the potential of repositories as content and service providers.

On another front, since 2016 DIGITAL.CSIC has been providing Digital Object Identifier (DOI) for institutional research data through DataCite. In fact, DIGITAL.CSIC gives a DOI to every single dataset that is uploaded in Open Access. This policy-together with Data Seal of Approval awarded in late 2015-have proved major incentives for CSIC researchers to make wider use of repository's data related services, and the volume of datasets available through DIGITAL.CSIC has experienced a steady growth ever since.

Most datasets available Open Access on DIGITAL.CSIC fall within Humanities, Natural Resources, Biology and Agricultural Sciences disciplines and are largely being opened as a requirement for publication of associated papers, as a result of adherence to H2020 open data pilot initiative or as an attempt to increase awareness and reuse of massive amounts of data that result from particularly prolonged research projects. In 2018, DOI availability expanded further so as to embrace research software and preprints, too, with irregular outcomes as of yet. Last but not the least, DIGITAL.CSIC has taken preliminary steps to surf the European Open Science Cloud (EOSC) wave and one initial effort in this direction is DIGITAL.CSIC involvement as data provider in European Plate Observing System (EPOS), an H2020 project that implements an operational and sustainable platform of Earth Science services.

This growing collaboration with several Open Science initiatives develops along with continued efforts to maintain research libraries relevant to institutional eyes and position them as central advocates and developers of innovative services (for instance, by contributing to LIBER Open Science Roadmap [9]). 


\subsection{Open Access Publishing Support Programme}

In Section 3 there will be a broad explanation about this programme, but now we would merely like to mention that CSIC Libraries and Archives Network is also committed to Open Access through its Publishing Support Programme for CSIC authors. It is offered as a financial aid to afford the costs of article processing charges (APC). Furthermore, it also raises awareness about Open Access amongst CSIC researchers, as well as it enriches DIGITAL.CSIC. Financial support for each article depends on the type of agreement reached with specific publisher. It also depends on whether it is based on membership, whether it applies a discount linked to annual subscription to publisher journals package (hybrid journals), and whether the agreement is with a Gold Open Access publisher. For the latter, URICI maintains a deposit account that subsidizes APCs.

Until the end of 2018, its budget represented a small portion of the total budget for institutional subscription payment. Agreements are made with hybrid publishers when negotiating annual licenses, which always require a \% discount on APCs, but no extra money is added to the subscription pot in order to cover those APCs. Rather, the growth of this Open Access Publishing budget has taken place thanks to provisions for Gold Open Access publishers.

\subsection{Supporting International Initiatives: arXiv, DOAJ, Knowledge Unlatched, SCOAP3}

URICI has been very sensitive towards all initiatives that arose from individual institutions or inside libraries consortia around the world in order to support Open Access publications. arXiv or DOAJ Directory are also financially supported from CSIC subscriptions budget. Likewise, a strong commitment is maintained with Knowledge Unlatched, with whom CSIC libraries network collaborates both in the annual collections costs payment as well as the titles selection process.

Regarding SCOAP3 project, CSIC role has been paramount in its success among Spanish universities and research libraries. In 2014, CSIC and the Consortium of University Libraries of Madrid (Madroño) led the process of data gathering and mapped and reconciled data with SCOAP3 publishers. At a later stage, they intermediated with each university and public research performing organizations in order to set up the Spanish governance within SCOAP3 and MOU signatures [10].

\section{Years of Open Access Publishing Support Programme for CSIC Authors}

\subsection{Creation, Development and Results (2008-2018)}

CSIC has been supporting Open Access publishing since 2008. That year, URICI included within its subscriptions budget a small amount for CSIC authors to publish in BioMed Central journals.

In 2013, URICI opted for GOLD x GOLD proposal of the Royal Society of Chemistry (RSC), which offered CSIC more than 50 vouchers to transform articles published behind a paywall to Open Access versions. The success of this model was gradual as few CSIC authors joined the initiative at the beginning. However, following librarians' efforts to disseminate this programme and related advantages, GOLD X GOLD was eventually settled amongst CSIC researchers. Nevertheless, RSC cancelled the programme in 2016, which generated many protests in CSIC community.

Between 2014 and 2015, F1000 Research and Science Advances joined the programme and also in 2014 an agreement was signed with MDPI in the form of a membership.

The collaboration with SCOAP3 started in 2014 and got renewed in all subsequent phases. It is considered part of this Programme, given that URICI pays the consortium from its subscription budget. The success of this initiative is without any doubt.

In 2017, a new subscription model with American Chemical Society provided APC discounts for CSIC's authors. In addition, Gold Open Access publisher Frontiers were also included in 2017. Finally, since 2018, Proceedings of the National Academy of Sciences (PNAS) institutional subscription facilitates APC discounts, too. As there has been a gradual diversification of publishers with whom CSIC has signed agreements, a growing number of researchers with different scientific backgrounds have benefited. 
Figure 3 covers the evolution of the associated budget in the period 2008-2018. In these 10 years, more than 3300 CSIC articles have benefited and in total URICI has contributed with $€ 378,557$. On 2008, the budget was $€ 12,000$ only. It has progressively grown and in 2018 it amounted to $€ 76,100$.

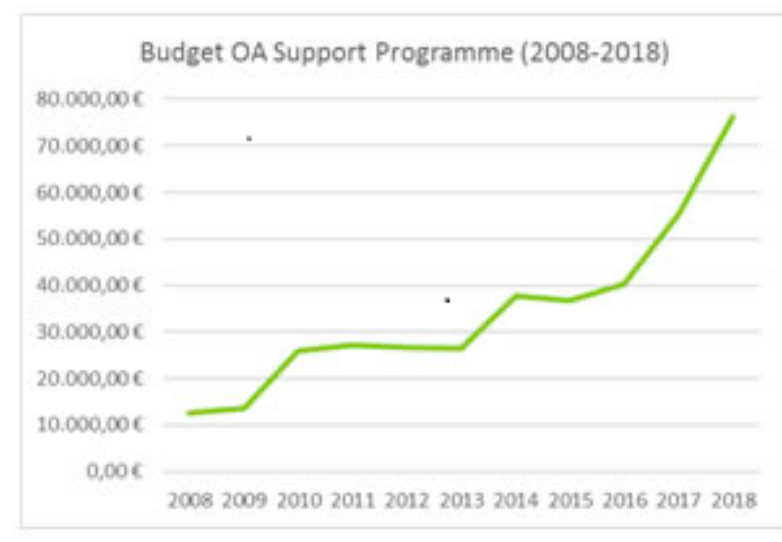

\begin{tabular}{|l|l|}
\hline \multicolumn{2}{|c|}{$\begin{array}{c}\text { Budget OA Support } \\
\text { Programme }\end{array}$} \\
\hline 2008 & $12.500,00 €$ \\
\hline 2009 & $13.644,09 €$ \\
\hline 2010 & $25.908,75 €$ \\
\hline 2011 & $27.204,19 €$ \\
\hline 2012 & $26.702,00 €$ \\
\hline 2013 & $26.390,00 €$ \\
\hline 2014 & $37.693,09 €$ \\
\hline 2015 & $36.737,52 €$ \\
\hline 2016 & $40.307,09 €$ \\
\hline 2017 & $55.370,37 €$ \\
\hline 2018 & $76.100,00 €$ \\
\hline & $378.557,10 €$ \\
\hline
\end{tabular}

Figure 3. CSIC Budget for Open Access Publishing Support Programme.

It is broadly accepted that the corresponding author's institution is the one that pays the APC [11]. But there are many factors that can influence the final APC prices: for instance, that a publisher grants a series of "free" articles to the institution, that a publisher applies extra discounts as the author also serves as a reviewer for the journal, or that the author of an article is a member of the publishing society. It is difficult to set up a real cost for APC [12]. Our conclusion is that, regarding the complete set of more than 33,000 Open Access articles published between 2008 and 2018 by CSIC's authors, the Open Access Publishing Support Programme granted a discount to 10\% of them (namely, 3346 articles). Figure 4 shows the distribution of such articles across different publishers and initiatives.

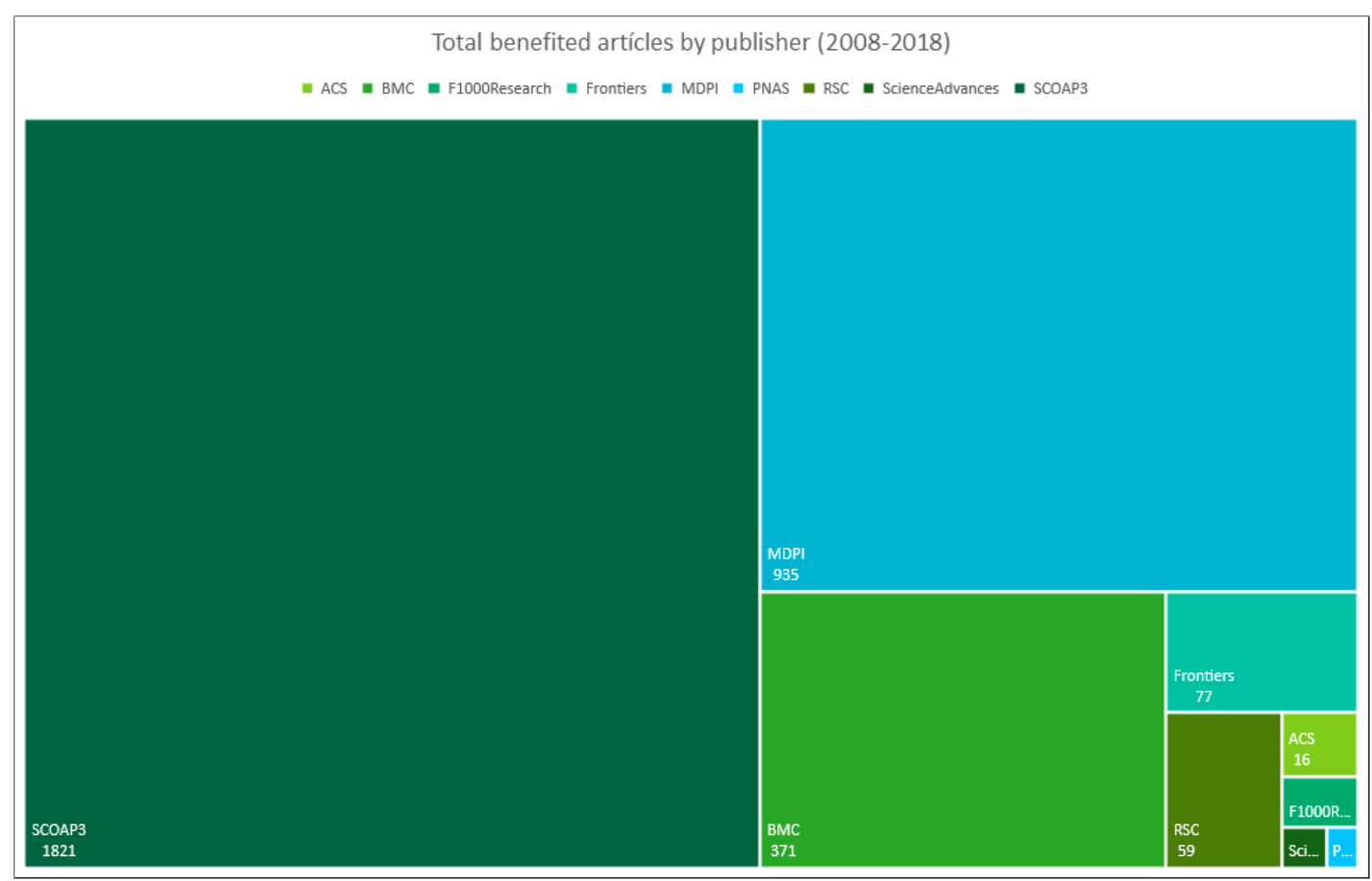

Figure 4. Total CSIC Articles by Publisher (2008-2018) that have benefitted from institutional Programme. 


\subsection{Programme Features}

There are two models from the author's point of view:

a. The author does not have to request URICI for any intermediation during the submission of their article. Publisher recognizes the CSIC author, usually thanks to the @ csic domain of her e-mail or from the affiliation data and automatically applies the discount. This is the case of MDPI, ACS and PNAS. For these, the number of articles to be subsidized is unlimited.

b. The author must request a verification from URICI in order to confirm to the journal the suitability to receive a discount. This is the case with Gold Open Access publishers, in which a pre-payment fund has been deposited from which a percentage of the APC is paid. Only one article is financed per year and author, due to limited resources in this programme. In these cases, the author uses a template that is accessed from the URICI intranet, and asks for a code that must be registered within the publisher site, or URICI confirms by e-mail that the APC discounts can be applied to the article.

Like other institutions with similar programmes, the conditions to benefit are the following:

- The article must have a CSIC corresponding author

- Authors must identify their CSIC affiliation in their signature

- Authors must send the paper from an IPN (Internet Protocol Number) that belongs to CSIC network

- Authors must use an institutional email with the @csic domain

- The article acknowledges the financial help of this programme

Table 1 gives an overview of all publishers with whom CSIC has reached institutional agreements and main features in each case. Each publisher participating in this Open Access Publishing Fund has its own workflow model.

In addition, URICI tries to supply as much information as possible about them for CSIC researchers. With this aim, there is a section devoted to Open Access in CSIC Library and Archives Network webpage [13], including a $30 \mathrm{FAQ}$ collection to clarify all possible doubts. 
Table 1. Summary of CSIC Open Access Publishing Support Programme in 2008-2018.

\begin{tabular}{|c|c|c|c|c|c|c|c|c|c|}
\hline Publisher & $\begin{array}{c}\text { Hybrid or } \\
\text { Gold } \\
\text { Publisher }\end{array}$ & $\begin{array}{c}\text { Active } \\
\text { Programme } \\
\text { Period }\end{array}$ & $\begin{array}{c}\text { \% APC Paid by } \\
\text { URICI }\end{array}$ & $\begin{array}{c}\text { Total articles } \\
\text { Granted } \\
(2008-2018)\end{array}$ & $\begin{array}{l}\text { Discount, Fund } \\
\text { or Membership }\end{array}$ & $\begin{array}{c}\text { Budget } \\
\text { 2008-2018 per } \\
\text { Publisher }\end{array}$ & $\begin{array}{l}\text { Who } \\
\text { Identifies the } \\
\text { Affiliations? }\end{array}$ & $\begin{array}{c}\text { Publisher-URICI } \\
\text { Communication }\end{array}$ & $\begin{array}{c}\text { Does Publisher } \\
\text { Submit Funded } \\
\text { Articles to } \\
\text { DIGITAL.CSIC? }\end{array}$ \\
\hline ACS & HYBRID & 2017- & $25 \%$ & 16 & $\begin{array}{l}\text { Discount/subscription } \\
\text { package }\end{array}$ & $0,00 €$ & Publisher & $\begin{array}{c}\text { URICI asks data } \\
\text { by email }\end{array}$ & $\mathrm{NO}$ \\
\hline BMC-SpringerOpen & n GOLD & $2008-$ & $\begin{array}{c}40 \% \text { (For } 2008 \text { to } \\
2013 \text { almost } 60 \% \text { ) }\end{array}$ & 371 & Fund & $242.753,46 €$ & CSIC & $\begin{array}{c}\text { Access to } \\
\text { publisher } \\
\text { administrative } \\
\text { portal }\end{array}$ & YES \\
\hline F1000 Research & GOLD & 2014- & $10 \%$ & 13 & $\begin{array}{l}\text { Discount/subscription } \\
\text { package }\end{array}$ & $0,00 €$ & Publisher & $\begin{array}{c}\text { URICI asks data } \\
\text { by email }\end{array}$ & $\mathrm{NO}$ \\
\hline Frontiers & GOLD & $2017-$ & $25 \%$ & 77 & Fund & $54.000,00 €$ & CSIC & $\begin{array}{c}\text { Monthly } \\
\text { reports/Access to } \\
\text { publisher } \\
\text { administrative } \\
\text { portal }\end{array}$ & YES \\
\hline MDPI & GOLD & 2014- & $25 \%$ & 935 & Membership & $8.624,00 €$ & Publisher & $\begin{array}{c}\text { Monthly } \\
\text { reports/Access to } \\
\text { publisher } \\
\text { administrative } \\
\text { portal }\end{array}$ & YES \\
\hline PNAS & HYBRID & 2018- & $25 \%$ & 4 & $\begin{array}{l}\text { Discount/subscription } \\
\text { package }\end{array}$ & $0,00 €$ & Publisher & $\begin{array}{c}\text { URICI asks data } \\
\text { by email }\end{array}$ & $\mathrm{NO}$ \\
\hline RSC & HYBRID & 2013-2016 & $100 \%$ & 59 & $\begin{array}{l}\text { Discount/subscription } \\
\text { package }\end{array}$ & $0,00 €$ & CSIC & Monthly reports & $\mathrm{NO}$ \\
\hline $\begin{array}{c}\text { Science } \\
\text { Advances }\end{array}$ & GOLD & 2015-2017 & among $\$ 150-\$ 450$ & 6 & $\begin{array}{l}\text { Discount/subscription } \\
\text { package }\end{array}$ & $0,00 €$ & Publisher & $\begin{array}{c}\text { URICI asks data } \\
\text { by email }\end{array}$ & $\mathrm{NO}$ \\
\hline SCOAP3 & GOLD & 2014- & $100 \%$ & 1821 & Membership & $73.179,64 €$ & Publisher & $\begin{array}{c}\text { Access to } \\
\text { publisher } \\
\text { administrative } \\
\text { portal }\end{array}$ & $\mathrm{NO}$ \\
\hline
\end{tabular}




\subsection{About the Workflow}

It is normal to find reflections in the professional literature about the increasing amount of workload that APC management generates at libraries [14]. In our 10-year-long experience, we can highlight the following problems:

- Publishers have huge difficulties in identifying authors or articles of the institution that should benefit from the discount agreements signed with the library.

- There is a hard relationship between library and researchers when it is mandatory to establish limits on the number of articles financed, or on compliance with some of the conditions that regulate the Programme.

- Each publisher has its own model or system to process institutional discounts in the APCs. This is confusing both for researchers and librarians.

- The library receives few (or no) information about the paper's review situation, which sometimes causes a part of the Open Access fund to be locked, without knowing if the article will eventually be accepted.

- Most publishers refuse to accept that the library, or the institution, introduces messages on their submission platforms. This could help authors to better understand how these funds work.

It is important that the issue of workflows be addressed from the outset of negotiation procedures. It is paramount that direct communication exists between the staff responsible for the OA workflow in publisher's side and the staff that takes care of this workflow in the library side.

The Open Access Publishing Programme has completed a 10-year period overcoming unfavourable circumstances: it has been really scarce, "lent" from the subscriptions budget, and with hardly any tools or personnel to deal with the extra workload. However, success among researchers has been growing. In 2018 they themselves demanded that it be expanded with more publishers and more journals.

New perspectives for the initiative may be foreseen from 2019, since CSIC has the intention to financially supplement this fund with a higher budget. In fact, it is included in CSIC's political commitment with Open Science.

\subsection{Interaction with DIGITAL.CSIC}

CSIC Open Access Publishing Support Programme has extended rapidly over the last few years. In general, CSIC authors have resorted to this institutional programme in order to comply with Open Access mandates whenever their projects have not budgeted Open Access publishing fees. Otherwise, preference to publish in Open Access stems mostly from prestige and journal impact factors.

A unique feature in CSIC Open Access Fund is its close interdependency with DIGITAL.CSIC. Both programmes came to light in 2008 and from 2012 a gradual interconnection between them has been put in place. In fact, in 2012 the eligibility criteria of institutional Open Access Fund were revisited to require a commitment from CSIC authors to participate in DIGITAL.CSIC as a condition to receive financial support. Specifically, CSIC authors who wish to apply for funding must have a minimum of five Open Access works on the repository, regardless of output type. What is more, funded authors also commit themselves to adding their outputs produced in the last 3 years in DIGITAL.CSIC at a second stage, once their article is funded and published. Most authors have benefitted from the institutional mediated archiving service provided by the DIGITAL.CSIC team and network of CSIC libraries to meet this obligation.

From the outset of the CSIC Open Access Publishing Support Programme, DIGITAL.CSIC has played an active role to facilitate that CSIC authors take advantage of the programme, by informing them about how to apply, giving advice on the most appropriate Open Access licenses and double-checking that authors are eligible to participate in the programme. As the institutional fund grew, so did the associated workload, which led to a redistribution of tasks amongst members of the small team of librarians under the e-resources subscription programme and DIGITAL.CSIC team. As a result, the former validates CSIC authors applications, follows up with queries and manages the fund, and the 
latter is in charge of checking and enabling compliance with related eligibility prerequisites and authors obligations once their articles are published.

Some institutional agreements in this programme include publishers' commitment to importing funded articles into DIGITAL.CSIC via SWORD protocol. Our experience with such service has been irregular thus far, considering that the set-up of this mechanism has often been lengthy, imports of duplicated articles have abounded, and metadata granularity of imported articles has been rather limited.

On another front, benefitting authors are requested to include a mention to CSIC Open Access Publishing Support Programme in the acknowledgements of their funded articles. DIGITAL.CSIC codifies this information in its funder metadata to better track and analyze its reach.

Overall, connecting the institutional publishing support initiative with the repository has been quite positive. Two main goals have been achieved by monitoring and supporting funded authors to open up their recent outputs via DIGITAL.CSIC: on one hand, it has proved an effective path to increase the rate of Open Access contents on the repository; on the other hand, a close interaction between the two Open Access routes at CSIC has been reinforced and made visible to the eyes of institutional authors.

\section{Analysis of Open Access to CSIC Publications}

\subsection{Methodology and Scope}

Mentions to "CSIC Open Access articles" refer to articles published in either Gold or Hybrid journals. Our analysis about Open Access publication trends and characteristics amongst CSIC authors includes these two options. In addition, the study completes with progress of Open Access green route, and Section 4.3 is fully dedicated to studying volume of CSIC research articles made available in Open Access through repositories.

Conclusions in this article are based on data generated with GesBIB, an internal, in-house development tool that integrates bibliographic information about CSIC publications as well as data from several external APIs, including Unpaywall, DOAJ, and Sherpa Romeo. The data analyzed in this study were retrieved in March 2019.

For finding publications, GesBIB gathers information from Web of Science and Scopus, so we have to consider that:

- We can only retrieve information from a publication once it has been indexed in these sources. So, there is a time gap from the date of publication and the date it is harvested.

- Some research areas like Humanities are not as well represented in these sources as other areas. Same case here for journals in languages other than English. An extensive bibliography acknowledges these limitations [15].

- Inside GesBIB, information is processed and enriched following this iterative process:

For each CSIC institute, we store one or more search queries for each source (WOS and Scopus) that define a set with all its publications.

- Then, results obtained through the APIs for each query are stored and matched so that only unique publications are considered. Each "clean" and unique publication can have WOS records and/or Scopus records linked.

$\bigcirc \quad$ For each publication, authors and affiliations of their linked records are processed. Those recognized as CSIC authors and affiliations are extracted while the rest are ignored.

- The extracted authors are matched and joined so that all the name variations of the same author are linked to a single CSIC author. Also, each author gets linked to all of their institutes based on affiliations found in their publications.

Once affiliations are recognized for a CSIC institute, they are stored and linked to it. 
- For each publication, GesBIB analyzes the "Correspondence" (Scopus) and/or "Reprint" (Web of Science) fields to search if any of CSIC authors for that publication appears in it. If so, that author is marked as "Corresponding Author" for that publication.

- Also, for each publication, additional information is harvested through external APIs and stored:

Open Access information: we use the Unpaywall and DOAJ APIs to determine if a publication has a freely available full text version (namely, Preprint, Postprint or Publisher's):

- Published (available through the publisher's platform): Gold or Hybrid Open Access.

- Self-archived and available in a repository: Green Open Access.

Sherpa/Romeo: we use it to determine if a source or publisher allows self-archiving and restrictions to be applied.

- For Unpaywall API we also took into account the following issues:

$0 \quad$ If an Open Access publication has not been harvested by Unpaywall yet, we do not get any results from the API and therefore we do not consider it Open Access.

- To date, Unpaywall API does not clearly distinguish non full-text files that may be attached to items on repositories from those files that are full-text copies. This is the case, for instance, with those files that are attached to restricted access items in many DSpace repositories to inform about the unavailability of a free full text copy of the record. Therefore, in order to get reliable data on volume of DIGITAL.CSIC items with full text files, we filtered Unpaywall results accordingly.

- We considered a journal as Gold Open Access if it exists in DOAJ or it is reported as Open Access in Unpaywall. The rest of journals with at least one article in Open Access on publisher's site (according to Unpaywall) are considered Hybrid Open Access.

\subsection{Analysis of CSIC Research Published in Open Access}

Between 2008 and 2018, researchers from CSIC institutes published more than 142,000 publications altogether (irrespective of whether they were corresponding authors) and a large majority of them can be classified as research articles, namely over 114,000.

Most research articles were published behind a paywall considering that in total only about 33,300 chose Gold or Hybrid Open Access options. Despite its relatively small representation (namely, 29\% of all research articles in the period under analysis), a steady acceleration in Open Access publishing has been observed over the last 5 years (Figure 5). As a result, CSIC authors have published around 3720 Open Access articles on average per year since 2014. Multiplication of new Open Access titles, including a spread of hybrid Open Access options, along with growing awareness about Open Access amongst CSIC researchers may have contributed to consolidate this phenomenon.

Generally speaking, CSIC research articles gather significant volume of citations. Whereas WoS reports more than 2,171,000 for the decade under analysis, Scopus counts over 2,400,000; this difference results from their varying databases of indexed journals.

What is worth noting is that, in comparative terms, Open Access research articles garner quite a large portion of citations, and median citation average is higher for Open Access articles. In fact, they boast between 690,000 citations according to WoS and 766,000 as reported by Scopus-that is, about $31 \%$ of total citations received by all CSIC research articles published between 2008 and 2018. This observation goes in line with a host of studies that evidence an Open Access citation advantage [16]. A closer look into the data (see Figure 6 and associated Table 2) also reveals that such citation advantage consolidates through the years analyzed, as an increase in median citation average is reported by the two bibliographic databases. 


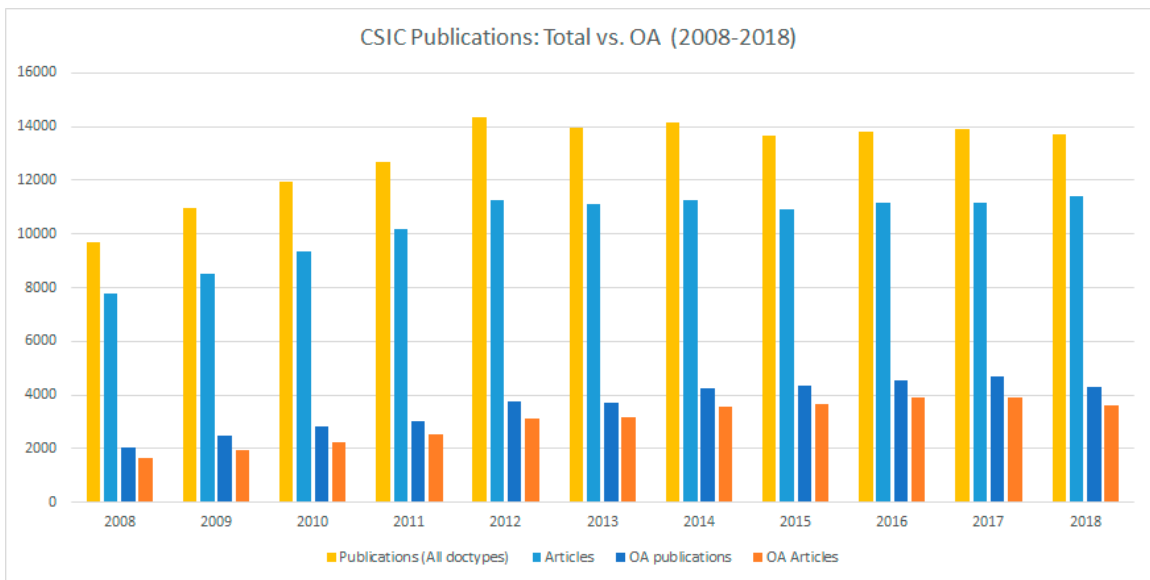

Figure 5. Graph with evolution of Open Access publishing at CSIC between 2008 and 2018.

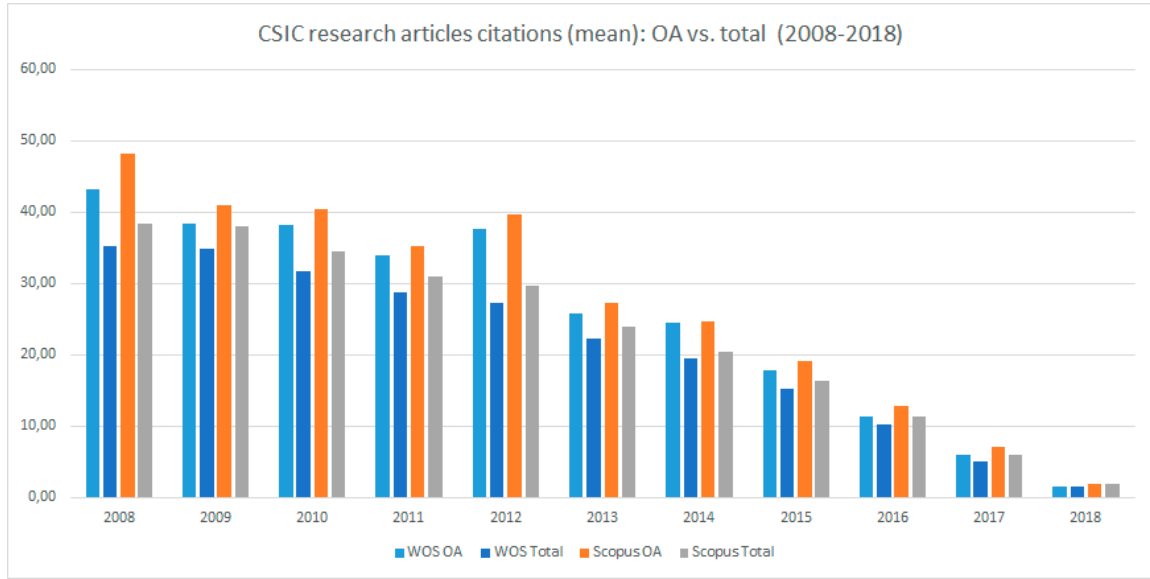

Figure 6. Overview of mean citations of CSIC articles published in Open Access according to Web of Science (WoS) and Scopus. Comparison with mean citations of total CSIC research articles.

Table 2. Mean citations (values) of CSIC articles published in Open Access according to WoS and Scopus. Comparison with mean citations of total CSIC research articles.

\begin{tabular}{ccccc}
\hline \multicolumn{5}{c}{ CSIC Research Articles Citations: Published in OA vs. Total (2008-2018) } \\
\hline Year & WOS OA & WOS Total & Scopus OA & Scopus Total \\
\hline 2008 & 4316 & 3512 & 4820 & 3841 \\
2009 & 3840 & 3487 & 4101 & 3796 \\
2010 & 3818 & 3174 & 4031 & 3449 \\
2011 & 3385 & 2876 & 3522 & 3091 \\
2012 & 3755 & 2727 & 3970 & 2960 \\
2013 & 2578 & 2223 & 2723 & 2388 \\
2014 & 2445 & 1954 & 2471 & 2040 \\
2015 & 1786 & 1511 & 1913 & 1634 \\
2016 & 1126 & 1024 & 1272 & 1135 \\
2017 & 598 & 500 & 707 & 587 \\
2018 & 154 & 145 & 193 & 180 \\
Mean $(2008-2018)$ & 2527 & 2103 & 2702 & 2282 \\
\hline
\end{tabular}

All in all, CSIC researchers published about 19,000 Open Access research articles in the last 5 years (2014-2018). Although they are distributed across a huge variety of publishers, including legacy, emerging and academic societies, more than $93.5 \%$ of such articles concentrate in the hands of a few publishers. Publication in Springer journals heads the TOP20 Publishers listing (see Table 3), followed by 
PLOS and top commercial subscription-based companies (Nature Research, Elsevier, OUP and Wiley). In addition to PLOS, other Gold Open Access publishers rank high in this classification, including MDPI, Frontiers, as well as diamond Open Access publisher Consejo Superior de Investigaciones Científicas.

Table 3. CSIC Research Articles published in Open Access 2014-2018: TOP20 Publishers.

\begin{tabular}{cc}
\hline TOP20 Publishers & CSIC Open Access Research Articles \\
\hline Springer (including Biomed Central and SpringerOpen) & 2596 \\
Public Library of Science & 1808 \\
Nature Research (part of Springer Nature) & 1703 \\
Oxford University Press (OUP) & 1532 \\
Elsevier & 1486 \\
Wiley (including Wiley Open) & 1077 \\
MDPI & 1057 \\
Frontiers Media & 923 \\
EDP Sciences & 837 \\
American Physical Society & 742 \\
Royal Society of Chemistry & 674 \\
American Astronomical Society & 614 \\
Consejo Superior de Investigaciones Científicas (CSIC) & 540 \\
European Geosciences Union (EGU) & 375 \\
American Society for Microbiology & 361 \\
IOP Publishing & 307 \\
American Chemical Society & 214 \\
Taylor \& Francis (including T\&F Open) & 194 \\
Hindawi Publishing Corporation & 184 \\
Cell Press & 180 \\
TOTAL & 17,404 \\
\hline
\end{tabular}

Furthermore, the volume of CSIC Open Access articles published in journals that run not-for-profit, membership models as well as discipline-focused societies such as the American Physical Society, American Astronomical Society, American Society for Microbiology and European Geosciences Union, is remarkable. Nevertheless, it is also important to keep in mind that some of these scientific societies delegate publication onto legacy publishers totally or partially. This is certainly the case with the American Astronomical Society.

Thus, over the last decade, CSIC authors have published their Open Access articles in Gold Open Access and Hybrid Journals alike. However, a slight predominance of the latter option has been registered and, in fact, from 2008 onwards preference for hybrid journals has been clear as far as the sheer number of titles are concerned. It may be interesting to further examine the underlying motivations for this publishing trend; a hypothesis may point at the relative low number of Gold Open Access journals 10 years ago in contrast with amount of Hybrid journals available and also at higher Journal Impact Factors of Hybrid journals. Nonetheless, if we look closer into the data (see Figure 7) we can distinguish a turning point in 2017, when the number of Gold journals where CSIC authors publish exceeds number of Hybrid titles where institutional researchers publish in Open Access. This change in behavior consolidated in 2018.

Although CSIC authors have overall preferred publishing in Hybrid Open Access journals over the last decade, two Gold Open Access journals, namely PLoS ONE and Scientific Reports, lead the ranking of TOP20 journals with more CSIC Open Access articles (see Table 4). These two titles together exceed 2500 CSIC articles over the last 5 years. Furthermore, on this ranking we do find more Gold titles than Hybrid ones. Another remarkable aspect on this list refers to the somewhat notable presence of journals already present in CSIC Open Access Publishing Support Programme. This is the case of High Energy Physics journals that fall under SCOAP3 initiative (which, to some extent, may be 
explained by the particularly high percentage of CSIC publications that belong to Physics, as indicated in Section 1, and Frontiers titles and such consideration will be further examined in sections below.

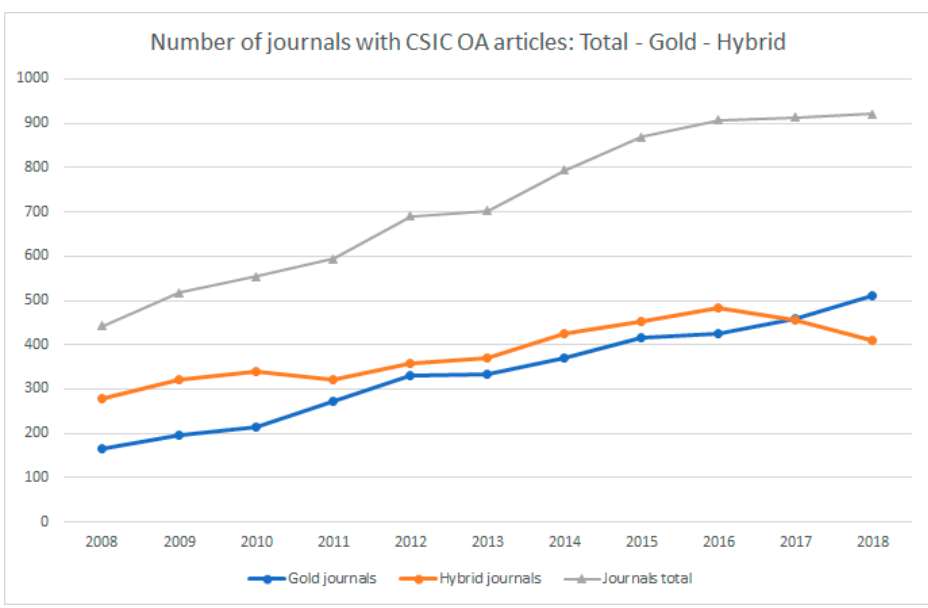

Figure 7. Graph of the evolution of CSIC publishing in Gold and Hybrid Journals in 2008-2018.

Table 4. TOP20 Journals with CSIC Research Articles in Open Access, 2014-2018.

\begin{tabular}{|c|c|c|c|}
\hline Journal & Publisher & Type (Nowadays) & $\begin{array}{l}\text { CSIC Research Articles } \\
\text { Published in Open Access }\end{array}$ \\
\hline PLoS One & Public Library of Science & Gold & 1517 \\
\hline Scientific Reports & Nature Research & Gold & 1075 \\
\hline $\begin{array}{l}\text { Journal of High Energy } \\
\text { Physics }\end{array}$ & Springer & Gold & 802 \\
\hline Astronomy \& Astrophysics & EDP Sciences & Hybrid & 796 \\
\hline European Physical Journal C & Springer & Gold & 439 \\
\hline Physics Letters B & Elsevier & Gold & 437 \\
\hline $\begin{array}{l}\text { Monthly Notices of The Royal } \\
\text { Astronomical Society }\end{array}$ & OUP & Hybrid & 410 \\
\hline Astrophysical Journal & $\begin{array}{l}\text { American Astronomical } \\
\text { Society }\end{array}$ & Hybrid & 387 \\
\hline $\begin{array}{c}\text { Physical Review D. Particles, } \\
\text { Fields, Gravitation, and } \\
\text { Cosmology }\end{array}$ & American Physical Society & Hybrid & 372 \\
\hline Nature Communications & Nature Research & Gold & 323 \\
\hline Frontiers in Microbiology & Frontiers Media & Gold & 254 \\
\hline Frontiers in Plant Science & Frontiers Media & Gold & 232 \\
\hline Physical Review Letters & American Physical Society & Hybrid & 218 \\
\hline Nucleic Acids Research & OUP & Gold & 194 \\
\hline $\begin{array}{l}\text { Proceedings of The National } \\
\text { Academy of Sciences }\end{array}$ & National Academy of Sciences & Hybrid & 167 \\
\hline Sensors & MDPI & Gold & 142 \\
\hline Plos Genetics & Public Library of Science & Gold & 127 \\
\hline BMC Genomics & Biomed Central & Gold & 125 \\
\hline Astrophysical Journal Letters & $\begin{array}{l}\text { American Astronomical } \\
\text { Society }\end{array}$ & Hybrid & 124 \\
\hline New Journal of Physics & IOP Publishing & Gold & 123 \\
\hline
\end{tabular}


It is eye-catching the way some titles have lost positions as time has passed by and have been replaced by other journals by CSIC authors' preferences. For instance, although PLoS One maintained a predominant position in terms of number of CSIC articles over 5 years, it lost first position in 2016 when it was replaced by Scientific Reports. We may find a convincing explanation for such change as we examine Impact Factor evolution of these two titles over the last few years: in fact, PLoS One Impact Factor fell dramatically whereas at the same time Scientific Reports Impact Factor increased rapidly (see Figure 8).
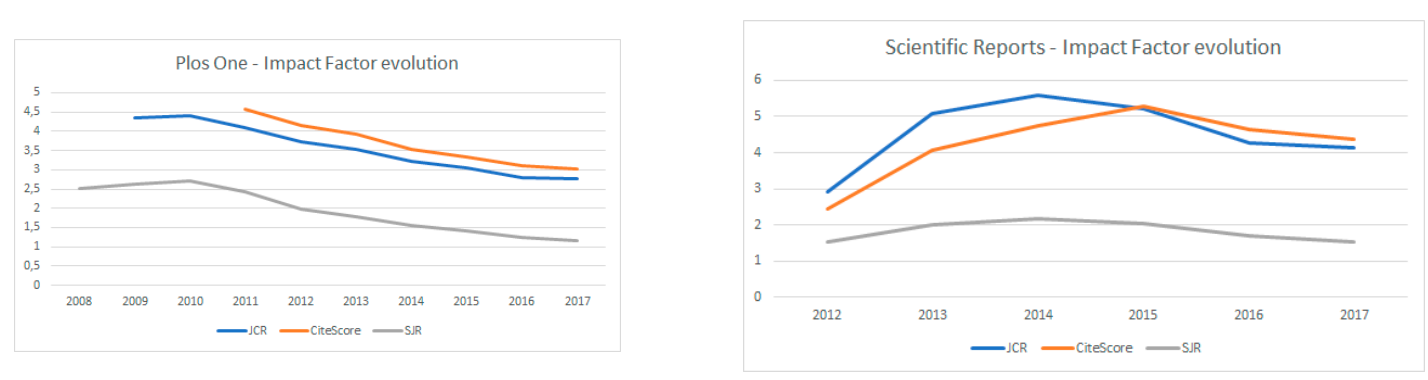

Figure 8. Graph with evolution of Impact Factor for PLoS One and Scientific Reports.

The abundance of Physics journals on the TOP20 list on Table 4 (as well as on Table 5 where a chronological evolution of positions of TOP10 journals with CSIC research articles is displayed), only reinforces the evidence of wide acceptance of Open Access publishing options amongst CSIC physicists. Last but not the least, progressive uptake of the most cited multidisciplinary open science journal in the world, Nature Communications [17], is all the more telling, in spite of requiring over $€ 4,000$ as article processing charges.

Table 5. Journal position by volume of CSIC Open Access Articles in 2014-2018.

\begin{tabular}{|c|c|c|c|c|c|c|}
\hline Journals & 2018 & 2017 & 2016 & 2015 & 2014 & $\begin{array}{c}\text { Total Position } \\
\text { 2014-2018 } \\
\text { Accumulated }\end{array}$ \\
\hline PLoS One & 3 & 3 & 2 & 1 & 1 & 1 \\
\hline Scientific Reports & 1 & 1 & 1 & 4 & 10 & 2 \\
\hline Journal of High Energy Physics & 2 & 2 & 3 & 3 & 3 & 3 \\
\hline Astronomy \& Astrophysics & 11 & 4 & 4 & 2 & 2 & 4 \\
\hline European Physical Journal C & 5 & 5 & 6 & 8 & 7 & 5 \\
\hline Physics Letters B & 7 & 6 & 5 & 7 & 6 & 6 \\
\hline $\begin{array}{l}\text { Monthly Notices of The Royal } \\
\text { Astronomical Society [*] }\end{array}$ & 20 & 13 & 42 & 5 & 4 & 7 \\
\hline Astrophysical Journal & & 7 & 7 & 6 & 5 & 8 \\
\hline $\begin{array}{l}\text { Physical Review D. Particles, Fields, } \\
\text { Gravitation, and Cosmology }\end{array}$ & 4 & 9 & 8 & 9 & 9 & 9 \\
\hline Nature Communications & 6 & 11 & 9 & 10 & 11 & 10 \\
\hline
\end{tabular}

[*] It is mandatory to comment that this journal had many publications in 2013-2015 and then the number fell dramatically; however, in the accumulated ranking the journal continues giving position 7.

\subsection{Reach of Green Route at CSIC: Publications Available through Open Access Repositories}

Our analysis about recent Open Access publishing at CSIC combines with an outline about trends and volume of CSIC research articles made available in Open Access through repositories. This analysis considers both DIGITAL.CSIC and other repositories being used by CSIC researcher community. In addition to subject-based repositories that are quite popular amongst some CSIC researcher communities (such as arXiv in top position and REPEC to a lesser extent), it is important to bear in mind that a substantial amount of CSIC institutes are so-called hybrid entities and co-administered 
by universities. As a result, a remarkable percentage of CSIC researchers enjoy the possibility to self-archive their works in DIGITAL.CSIC alongside their respective university repository.

According to Unpaywall (see Table 6), close to 25,000 journal articles by CSIC researchers between 2008 and 2018 and behind a publisher paywall have a full text copy on a repository_DIGITAL.CSIC has a copy of more than 19,000 of those. This figure represents around a fifth of total journal articles by CSIC authors in this time span and slightly falls behind volume of CSIC journal articles published in Open Access in the last decade. In total, the combination of the two routes (Gold/Hybrid publication and repositories) adds up to close to 60,000 CSIC research articles that are already available in Open Access.

Table 6. Number of CSIC research articles under a publisher's paywall and available in Open Access repositories. Source: Unpaywall.

\begin{tabular}{cc}
\hline Date of Publication & CSIC Research Articles \\
\hline 2008 & 1755 \\
2009 & 1723 \\
2010 & 2280 \\
2011 & 2830 \\
2012 & 3154 \\
2013 & 3284 \\
2014 & 2033 \\
2015 & 2090 \\
2016 & 2210 \\
2017 & 1926 \\
2018 & 1572 \\
\hline
\end{tabular}

A closer look to distribution of CSIC authors' manuscripts in Open Access repositories in Table 6 sees a concentration in the years 2010-2016. A tentative explanation may have relation with impact of journals self-archiving policies. Thus, in the early years, rather constrained self-archiving policies were commonplace amongst many subscription publishers, whereas a large portion of articles published over the last 2 years are yet under publishers' embargo restrictions. In this regard, it is important to note that Unpaywall fails to identify embargoed articles in repositories as Green Open Access and this limitation may be behind the decrease of number of CSIC articles in Open Access repositories over the last two years under analysis.

If we turn our attention towards DIGITAL.CSIC performance, some conclusions may be drawn. Although a handful of subject-based repositories enjoy solid reputation amongst identifiable scientific groups at CSIC, DIGITAL.CSIC is by far the preferred repository by CSIC researchers who wish to make their works available Open Access or are obliged to do so by funders' mandates. One explanation lies in the take-up of so-called Delegated Archiving Service offered by DIGITAL.CSIC Technical Office and network of CSIC libraries that release CSIC researchers from all activities associated with upload of contents onto the repository. In fact, according to Unpaywall, $76 \%$ of the above mentioned 25,000 CSIC articles in Open Access through the Green route have a copy on DIGITAL.CSIC.

Nonetheless, the number of CSIC research articles with a free full-text copy attached on DIGITAL.CSIC rises as we consider total amount of this research type, irrespective of publication year, and count all possible versions available for free (that is to say, publisher final copy, preprint and author-accepted manuscript). At time of writing this article, there were a bit more than 100,000 items on the repository that fall under the category of "journal article" regardless of their publication year. More than 60,000 of them carry a full text file whereas another 900 are currently under a publisher embargo.

As Figure 9 shows, more than half of total research articles (namely, a bit more than 54,000) are concentrated in the hands of 20 publishers, with 20,000 Elsevier articles leading this classification and followed, at a considerable distance, by Springer, American Chemical Society and American Physical Society articles. This classification somehow mirrors main trends of CSIC authors publishing habits, 
namely, a clear overall preference for large publishers of subscription journals and a relatively significant presence of a few Gold Open Access publishers: PLoS, Biomed Central, MDPI and Frontiers Media.

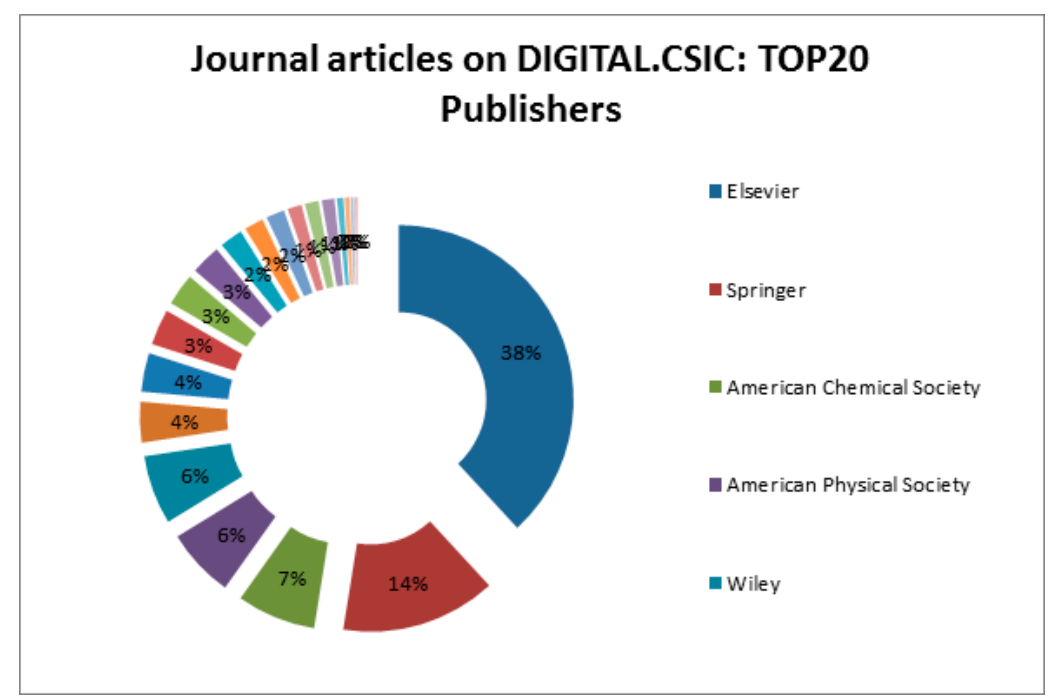

Figure 9. Distribution of CSIC research articles on DIGITAL.CSIC by publisher. Source: DIGITAL.CSIC.

Current analysis sheds light on a notable volume of CSIC journal articles that can be accessed for free nowadays. As time has passed and the very concept of Open Access has gained traction, more and more researchers have taken advantage of different Open Access channels to disseminate their works.

This growing acceptance of Open Access is clearly supported by analyzed data yet a higher percentage of CSIC research could be already freely accessible provided institutional authors maximized all possibilities at their disposal. Thus, according to data retrieved from DOAJ and Unpaywall, around 60,000 CSIC publications from the last 10 years are already openly accessible and an extra 44,000 research articles that are currently available through subscription could be made Open Access through deposition in a repository according to data by Sherpa Romeo API, as Table 7 shows. This tentative conclusion puts a strong emphasis on the opportunities that green route offers at no additional cost to dramatically increase the volume of publications available for free through trustworthy repositories. The other side of the coin, however, may be that such practice be accompanied by relatively lengthy embargo periods imposed by publishers or some uncertainty over use license attached to full text copies made available in repositories.

Table 7. Volume of CSIC research articles that could be made Open Access via repository deposit. Source: Sherpa Romeo.

\begin{tabular}{cc}
\hline Date of Publication & CSIC Research Articles \\
\hline 2008 & 3633 \\
2009 & 3930 \\
2010 & 3572 \\
2011 & 3566 \\
2012 & 3623 \\
2013 & 3330 \\
2014 & 4561 \\
2015 & 4045 \\
2016 & 3911 \\
2017 & 4327 \\
2018 & 5689 \\
\hline
\end{tabular}


4.4. Relation between CSIC Open Access Publishing Support Programme Results and Total Number of CSIC Open Access Publications (2008-2018)

As mentioned in Section 3, the amount devoted to institutional Open Access Publishing Support Programme has been small over these 10 years. We are now in a position to analyze its impact over all CSIC Open Access publications thanks to GesBIB, a tool capable to provide insights from different angles. In last 10 years, CSIC Open Access Publishing Support Programme has helped finance more than 3300 articles, which represents 10\% of the nearly 33,300 Open Access research articles published in the same period (see Figure 10).

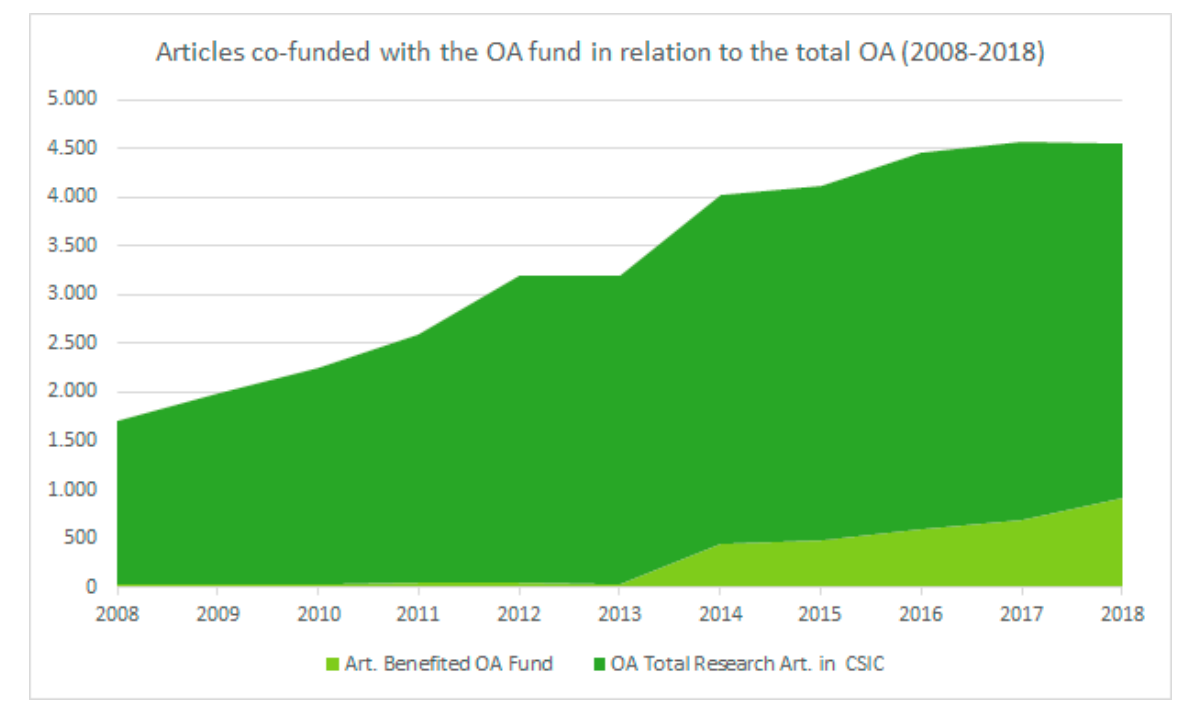

Figure 10. Articles under CSIC Open Access Publishing Support Programme compared with total CSIC Open Access Articles (2008-2018).

\section{Current and Future Management of Journals Subscriptions}

URICI is responsible for carrying out acquisitions (both purchase and subscriptions) of all scientific information resources for CSIC Libraries and Archives Network. This department contracts annual hiring of databases, e-books, research tools and collections of printed journals, but the most important part of this negotiation covers e-journals packages. The 2017 annual investment for these e-journal licenses is around $€ 6.5$ million (€7.8 million VAT included). As a result, CSIC researchers are offered more than 11,500 titles. Every year, about 50 licenses are negotiated and contracted with the most relevant scientific publishers in the world and across all disciplines. There are a few licenses subscribed for a group of CSIC centers only, whereas others give access to the whole institution. In general, these are annual agreements; however, there are also multi-year licenses with 12 publishers. In addition, national agreements are reached with the three major companies (Springer, Wiley and Elsevier) and these negotiations involve university library consortia and Public Research Organizations [18].

In the Spanish academic environment, the investment made by CSIC in e-journals is one of the largest in the country. REBIUN, the Network of Spanish University Libraries, publishes annual statistics data that describe, among many other things, collections and expenses made by the libraries of 73 Spanish universities and CSIC. In 2017, all REBIUN libraries have expended $€ 63.5$ million (with VAT) subscribing electronic journals [19]. 12.28\% of this total is invested by CSIC.

In order to move from the subscription model to any other-whether considering offsetting, jumping to full Open Access, joining national Open Access agreements, or making any kind of transformative agreements - it is crucial to have accurate data so as to make informed decisions. Fortunately, CSIC currently has several of these insights, or can make a quite reliable approach to them:

- Number of publications with CSIC corresponding author (that is to say, publications behind a paywall and also Open Access publications, and their distribution by publisher) 
- Number of Open Access publications in every subscribed publisher, with corresponding author CSIC

- Estimated cost invested in APCs by the institution

For the purposes of drafting the following analyses, we use data on the number of articles and e-journals subscriptions referred to 2017. This paper has been written in March 2019. Regarding the tools that we are using (GesBIB, WoS, SCOPUS, etc.), 2017 data can now be considered as a stable, complete and closed set.

Figure 11 shows that, as far as Open Access is concerned, CSIC authors broadly publish in Gold journals (23\%). Despite this scenario, publishers do not include Gold journals in most of Read \& Publish or offsetting negotiations proposed to libraries. In their view, this type of journals has never been part of subscriptions portfolios, and therefore libraries have never paid any fee for them.

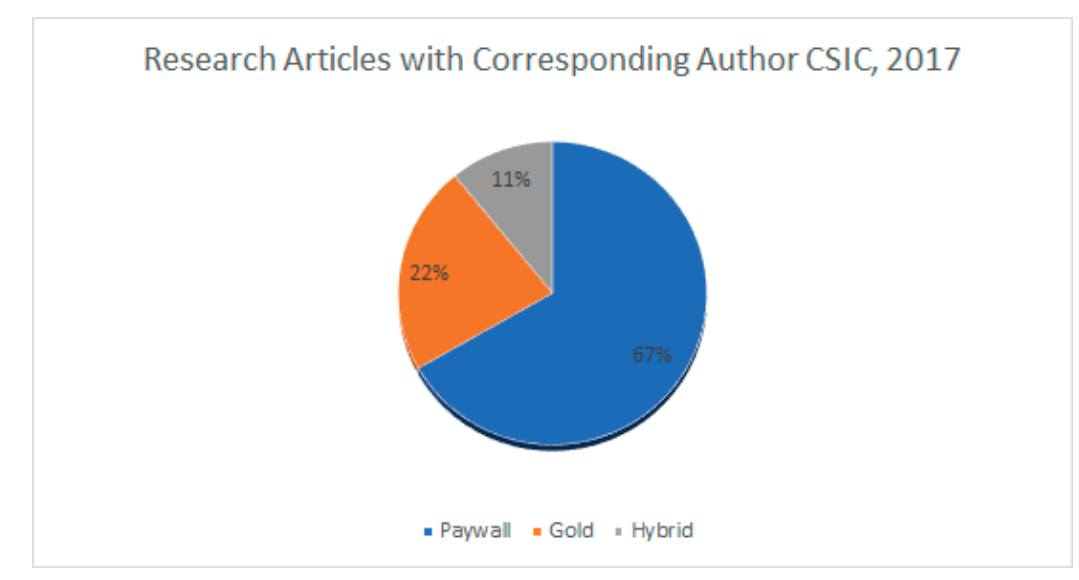

Figure 11. Research articles (total number: 5321) with CSIC corresponding author published behind a paywall or in Open Access (Hybrid or Gold).

Concerning Gold Open Access publishers, the list of preferred ones in 2017 was headed by Frontiers and MDPI, followed by Public Library of Science. These conclusions are important to bear in mind before making decisions regarding collection management and the future of CSIC Open Access Publishing Support Programme.

There were 5321 research articles with CSIC's corresponding author in 2017 and Figure 12 shows their distribution among the 10 main subscription publishers hired by URICI for CSIC Libraries Network. The figure also displays volume of articles that were published in Open Access as compared to total CSIC articles per publisher.

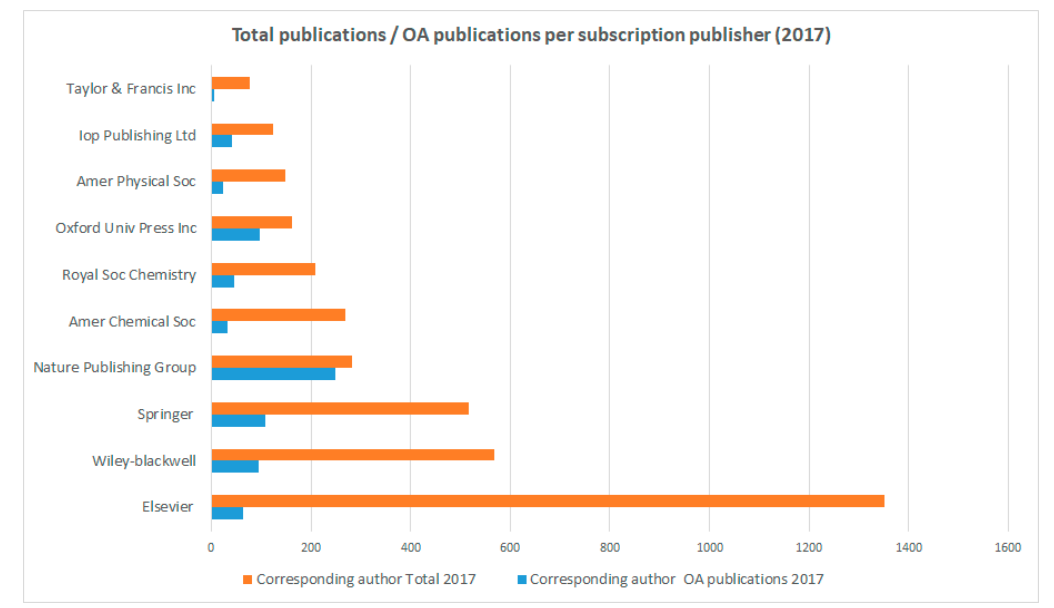

Figure 12. Total publications versus total OA publications, distributed by subscribed publisher. 
The striking case of Nature Publishing Group, where most CSIC articles with institutional corresponding author in 2017 were published in Open Access, is explained because this publisher is responsible for two of the most relevant journals in recent years, namely, Scientific Research (205 articles) and Nature Communications (23 articles), and both are Gold Open Access journals. Mean value for Nature Communications APCs amounted to $€ 3995$ [20] while APCs for Scientific Reports was $€ 1444$ [21] in 2017.

In view of decisions to be made by the CSIC subscription department, it is irrelevant whether these publications are in hybrid or gold journals. The fact is that there have been APCs paid by CSIC and that this cost should be included in calculations made when our department works on the renewal process for new agreements to come.

The analysis can also be completed with information about Open Access journals (Gold or Hybrid titles, or both) where most CSIC authors have published in 2014-2018 in relation to institutional Open Access Publishing Support Programme. Table 8 classifies TOP20 journals (2014-2018) with more Open Access articles.

Table 8. TOP20 Journals with CSIC Research Articles in Open Access, 2014-2018 in relation with Open Access Publishing Support Programme.

\begin{tabular}{|c|c|c|c|}
\hline Journal & Publisher & Type (Nowadays) & $\begin{array}{l}\text { CSIC Research Articles } \\
\text { published in Open Access }\end{array}$ \\
\hline PLoS One & Public Library of Science & Gold & 1517 \\
\hline Scientific Reports & Nature Research & Gold & 1075 \\
\hline Journal of High Energy Physics & Springer & Gold & 802 \\
\hline Astronomy \& Astrophysics & EDP Sciences & Hybrid & 796 \\
\hline European Physical Journal C & Springer & Gold & 439 \\
\hline Physics Letters B & Elsevier & Gold & 437 \\
\hline $\begin{array}{l}\text { Monthly Notices of The Royal } \\
\text { Astronomical Society }\end{array}$ & OUP & Hybrid & 410 \\
\hline Astrophysical Journal & $\begin{array}{l}\text { American Astronomical } \\
\text { Society }\end{array}$ & Hybrid & 387 \\
\hline $\begin{array}{l}\text { Physical Review D. Particles, } \\
\text { Fields, Gravitation, and } \\
\text { Cosmology }\end{array}$ & American Physical Society & Hybrid & 372 \\
\hline Nature Communications & Nature Research & Gold & 323 \\
\hline Frontiers in Microbiology & Frontiers Media & Gold & 254 \\
\hline Frontiers in Plant Science & Frontiers Media & Gold & 232 \\
\hline Physical Review Letters & American Physical Society & Hybrid & 218 \\
\hline Nucleic Acids Research & OUP & Gold & 194 \\
\hline $\begin{array}{l}\text { Proceedings of The National } \\
\text { Academy of Sciences }\end{array}$ & National Academy of Sciences & Hybrid & 167 \\
\hline Sensors & MDPI & Gold & 142 \\
\hline Plos Genetics & Public Library of Science & Gold & 127 \\
\hline BMC Genomics & Springer & Gold & 125 \\
\hline Astrophysical Journal Letters & $\begin{array}{l}\text { American Astronomical } \\
\text { Society }\end{array}$ & Hybrid & 124 \\
\hline New Journal of Physics & IOP Publishing & Gold & 123 \\
\hline $\begin{array}{c}\text { Atmospheric Chemistry and } \\
\text { Physics }\end{array}$ & $\begin{array}{l}\text { European Geosciences Union } \\
\text { (EGU) }\end{array}$ & Gold & 113 \\
\hline
\end{tabular}

The blue colour indicates whether the publication is part of CSIC Publishing Support Programme (that is to say, Frontiers, MDPI, BMC, PNAS, SCOAP3); the red colour, if the publication is the result of a Hybrid Open Access choice in a title that CSIC Libraries Network subscribes; the black, Gold 
publications (but without agreement under the umbrella of this programme yet). Regarding these cases, institutional policy for the future is to achieve agreements with Gold titles or Gold Publishers, or, eventually, with Hybrid titles or publishers as long as they prove a willingness to transform into Gold Open Access models in the short run. We do not attend to any request to pay individual articles of other kind of titles.

Of these 20 publications, 11 are already part of CSIC Open Access Publishing Support Programme and they have benefited to some extent from agreements with the publishers; 4 other journals are part of CSIC libraries annual subscription collection, so it would be convenient to reach discount agreements on APCs or offsetting in the renewal price; lastly, 6 of them are unrelated to the Programme. All these 6 are Gold journals and of extraordinary importance in the scientific world. These 20 titles concentrate the interests of the researchers of CSIC at the time of publishing in Open Access, and the future management of the subscriptions should take them into account.

Finally, as mentioned above, it is necessary to know, even in a rough way, an estimate of the budget invested in APCs by the institution. For this aim, GesBIB tool has incorporated DOAJ information on articles and mean values of APC by journal. In the 2008-2018 period, 6612 research articles by CSIC authors appear in DOAJ (without specifying if they were corresponding authors or else) and the mean value APC for these publications was $€ 1565$.81. A similar amount, $€ 1485$, is indicated in other recent professional publication [22]. If we refer strictly to the year 2017, Intact project's mean value was $€ 2000$ [23].

Since we already have a considerable amount of information in our hands, it is possible to draw the scenario for transformative agreements, as it is displayed in Figure 13. Two numerical data obtained from GesBIB are the basis for our calculation. These data are the number of Open Access research articles with CSIC corresponding author found in publisher's webs (1727 articles) and the mean value APCs (€1500). We did not have this information before.

\begin{tabular}{|c|c|c|c|c|c|}
\hline Year & $\begin{array}{l}\text { Total research } \\
\text { articles (RA) }\end{array}$ & \begin{tabular}{|l} 
RA, CSIC \\
Corresp. Author \\
(CA)
\end{tabular} & $\begin{array}{l}\text { APC } 1.500 €(5.321 \\
\times 1,500 €)\end{array}$ & $\begin{array}{l}\text { Subscriptions } \\
\text { expense (VAT } \\
\text { excl.) }\end{array}$ & $\begin{array}{l}\text { Increase over } \\
\text { subscriptions } \\
\text { expense }\end{array}$ \\
\hline 2017 & 11.184 & 5.321 & 7.981 .500 & 6.438 .674 & $-1.542 .825,65 €$ \\
\hline Year & $\begin{array}{l}\text { Total research } \\
\text { articles (RA) }\end{array}$ & \begin{tabular}{|l|} 
RA, CSIC \\
Corresp. Author \\
(CA) \\
\end{tabular} & \begin{tabular}{|l|} 
RA. OA, CA CSIC \\
(publisher version)
\end{tabular} & $\begin{array}{l}\text { APC } 1.500 €(1.727 \\
\times 1,500 €)\end{array}$ & \\
\hline 2017 & 11.184 & 5.321 & 1.727 & $2.590 .500,00 €$ & \\
\hline Year & $\begin{array}{l}\begin{array}{l}\text { Subscriptions } \\
\text { expense (VAT } \\
\text { excl.) }\end{array} \\
\end{array}$ & $\begin{array}{l}\text { APC } 1.500 € \\
(1.727 \times 1,500 €)\end{array}$ & SUM & & \\
\hline 2017 & $6.438 .674,35 €$ & $2.590 .500,00 €$ & $9.029 .174,35 €$ & & \\
\hline Year & \begin{tabular}{|l|} 
Subscriptions \\
expense + APCs \\
already paid by \\
CSIC \\
\end{tabular} & $\begin{array}{l}\text { APC } 1.500 € \\
(5.321 \times 1,500 €)\end{array}$ & FINAL BALANCE & & \\
\hline 2017 & $9.029 .174,35 €$ & $7.981 .500,00 €$ & $1.047 .674,35 €$ & & \\
\hline
\end{tabular}

Figure 13. Global Transformative Agreement in CSIC in 2017: A Hypothesis.

In order to present a global Transformative Agreement's hypothesis based on 2017 scenario, we follow these steps:

We need to know the cost of Open Access publishing for the 5321 research articles with CSIC corresponding author in $2017(5321 \times € 1500=€ 7,981,500)$

- We need to compare that amount $(€ 7,981,500)$ with CSIC's expenditure on e-journals subscriptions in 2017 (it was $€ 6,438,674$ ). The immediate conclusion, as observed in Figure 13, is that CSIC does not have enough money to approach a global transformative agreement. Apparently, an additional $€ 1,542,825$ would be needed. 
- However, it is possible to know, roughly, that CSIC corresponding authors have already paid $€ 2,590,500$ to publish 1727 research articles in Open Access (this amount is the result of 1727 art $\times$ $€ 1500$ APC)

The sum of this last amount $(€ 2,590,500)$ plus the annual cost per subscriptions $(€ 6,438,674)$ concludes that the total available budget in CSIC invested in scientific journals (subscribed + APCs already paid) is $€ 9,029,174$. This budget shows that CSIC could largely face a transition to publish all its publications in Open Access. As it is explained, the cost for publishing 5321 research articles in Open Access would be $€ 7,981,500$, and with $€ 9,029,174$ available there is a balance in favor of CSIC of more than one million euros. Obviously, it is necessary to count with the money that has already been paid in APCs directly by researchers, and this money is not now within the CSIC Libraries network's budget, unlike that of subscriptions.

As a lot of institutions have already done all over the world, CSIC has signed OA2020 Initiative and has taken it as its roadmap for the transition from the "pay per read/pay for publishing" model. CSIC also supports the Open Access Statement of SELL (Southern Europe Libraries Link) signed by the members of SELL in June 2018, after the celebration of its 18th Conference in Thessaloniki [24].

Moreover, national agreements signed by CSIC with three major publishers (Elsevier-Science Direct, Wiley and Springer) will finish at the end of 2019 and 2020. It is the decision of the Working Group involved in the negotiations of these national agreements to follow both recommendations by Spanish Foundation of Science and Technology (FECYT) [25] and those by LIBER Open Science Roadmap.

Taking into account this scenario, obviously, CSIC is in position to negotiate transformative agreements with publishers. In fact, while this article was being written, CSIC has already signed the first Read \& Publish Agreement in Spain. It has been with the Royal Society of Chemistry for the period 2019-2020 [26] and it has punctually been reported in the ESAC Registry [27]. At the same time, throughout 2019, CSIC is advancing in negotiations with other publishers to achieve individual agreements, while it also actively participates in the Working Group regarding transformative agreements at a national level, with other publishers.

\section{Conclusions}

CSIC is a high-intensive research-performing organization with remarkable publication performance and citations. Journal research article is the predominant type of output authored by CSIC and there is a consolidated habit to publish in high impact factor journals, mostly Q1 titles. In the last decade, CSIC published close to 115,000 research articles across all disciplines, and subscription-based journals have been clearly the preferred route. However, during the last decade interesting data shed light on gradual uptake of Open Access options, both via publication and self-archiving.

Analyzed data in the article gives much insight into impact of Open Access research articles, researchers' behavior as to Open Access publishing options, and participation in the Open Access Green route. In total, nearly 60,000 CSIC research articles dated between 2008 and 2018 are already available in Open Access, either through publisher platform or through an Open Access repository. This figure is quite significant in quantitative terms and reveals constant expansion of both Open Access routes, namely journals and repositories. Therefore, sustaining perceived dichotomy between the two canonical Open Access routes, however widely spread amongst some communities, poses unnecessary obstacles for those institutions whose goal focuses on maximizing Open Access to its research outputs. Thus, in order to get the full picture of availability of institutional research outputs in Open Access, data from the two routes must be jointly examined.

CSIC research articles published in Open Access gather on average higher citations than those published behind a paywall. Although Hybrid Open Access journals have enjoyed a long standing preference amongst CSIC researchers during the last decade-a decision that seems to have been largely determined by high journal impact factors, and by article processing charges to a lesser extent-a trend change was observed in 2017 where more CSIC research articles were published in Gold Open Access 
journals for the first time. In addition, it is worth noting that during the whole period under analysis, two mega-journals, namely PLoS One and Scientific Reports, have rivalled over the first position of TOP Open Access publishing preferences amongst institutional authors. This TOP classification also includes Open Access titles where CSIC has already been supporting publishing through its institutional fund.

Close to half of those 60,000 CSIC research articles from last decade that are already in Open Access are made so through authors manuscripts in Open Access repositories. In fact, a high volume of CSIC research articles can be accessed freely and permanently via a wide range of repositories types, institutional repository DIGITAL.CSIC being the one with the highest amount of such copies. Further, the quantity of CSIC research articles in Open Access through institutional repository more than doubles as we broaden criteria of publication year and article version. Mediated Archiving Service provided by DIGITAL.CSIC Technical Office and CSIC Libraries Network plays a remarkable role in organizing and securing a centralized and institutional gateway to CSIC publications for current and future generations. What is more, the total number of CSIC research articles available in Open Access through repository archiving could exceed 100,000, provided CSIC authors maximized journals' self-archiving policies. Raising even more awareness about such opportunities is a pressing need, also considering that CSIC authors sometimes choose APCs route to Open Access without knowing that there is a legal self-archiving policy in place.

On the other hand, the development of the Open Access Publishing Fund shows the growing success of an initiative that was presented as rather modest 10 years ago. The accumulated sum of the period has helped to cover $10 \%$ of CSIC Open Access articles in that period. The institutional fund has also played an important role to raise awareness amongst CSIC community about advantages of Open Access publishing, especially thanks to its interconnection with the repository. As it is said in the article, now the researchers perceive that both of them are facets of the same objective.

The achievements of Open Access Publishing Fund are also proven by the fact that it has influenced in the "TOP journal OA publishing preferences". The review of the trends in the type of Open Access publication chosen by the authors make us conclude that Gold journals should be included in future e-journals licenses negotiations. Publishers tend to leave them out, but there is a serious danger to create a parallel world with them without any libraries' influence. It is mandatory to say that APCs' management workflow has improved in these 10 years to a certain extent. However, some publishers are more collaborative with libraries, and the work overload is considerable and will be more so as the model becomes entrenched, and even dominates over the subscriptions' scenario.

The article has also focused on CSIC's investments in e-journals, in particular through a case study in 2017. In that year, $67 \%$ of CSIC research articles were behind a paywall but a strong $33 \%$ were published in Open Access (in Gold or Hybrid titles). These Open Access articles were paid by the authors or the institution.

Cross-matching information about APCs with 2017 subscriptions data has made clear that transformative agreements could be addressed without problems in institutions that publish a lot, like CSIC, because the consolidated trend is that each year there are more Open Access publications, as this study shows. Nevertheless, this is a global estimation.

From the point of view of those responsible for CSIC libraries e-journals management and development, and especially from the team that deals with institutional negotiations, it is now mandatory to add a new criterion to traditional ones before making decisions on what to subscribe and how. Until now, acquisition librarians took into account if there was a good cost-use ratio (price for downloading articles) or the suitability of a Big Deal, or the fight to abandon the prices inherited from the printed collection. Nowadays, however, the number of articles published by institutional authors with every single publisher, whether they have been published in Open Access, whether CSIC authors are the corresponding authors and who has covered the APCs, must join as an imperative criterion in order to make informed decisions. 
Author Contributions: Conceptualization, M.B.-A. and I.B.; methodology, M.B.-A. and I.B.; software, L.D.; validation, M.B.-A., I.B. and L.D.; formal analysis, M.B.-A. and I.B; investigation, M.B.-A. and I.B.; writing-original draft preparation, M.B.-A. and I.B.; writing-review and editing, M.B.-A., I.B. and L.D.

Funding: We acknowledge support by the CSIC Open Access Publication Initiative through its Unit of Information Resources for Research (URICI).

Acknowledgments: We want to thank Agnès Ponsati from Unit of Information Resources for Research (CSIC) for helpful comments on the final draft manuscript. We also thank valuable input provided by the reviewers during the editorial process.

Conflicts of Interest: The authors declare no conflict of interest.

\section{References and Note}

1. CSIC Annual Report 2017. Available online: http://digital.csic.es/handle/10261/173995 (accessed on 24 April 2019).

2. Spain's Ministry of Science. Available online: http://www.ciencia.gob.es/portal/site/MICINN?lang_choosen=en (accessed on 24 April 2019).

3. Data retrieved from CSIC internal tool GesBIB. Available online: http://bibliotecas.csic.es/gesbib (accessed on 24 April 2019).

4. Bordons, M.; Morillo, F.; Moreno-Solano, L.; Aparicio, J.; González-Albo, J. La actividad científica del CSIC a través de indicadores bibliométricos (Web of Science, 2013-2017). 2018. Available online: https://digital.csic.es/handle/10261/174014 (accessed on 24 April 2019).

5. Nature Index 2018. Available online: https://www.natureindex.com/annual-tables/2018/institution/all/all (accessed on 24 April 2019).

6. Institutional Green Open Access Mandate entered into force on 24 April 2019 1st, 2019. The Mandate Requires Immediate Deposit of Metadata upon Acceptance for Peer Reviewed Publications and Open Access to Full Text as Soon as Possible on Institutional Repository DIGITAL.CSIC. It also Requires Deposit of Metadata of Associated Datasets and Open them as Soon as Possible Unless Exceptions May Apply. Available online: https://digital.csic.es/handle/10261/179077 (accessed on 24 April 2019).

7. DIGITAL.CSIC Annual Reports. Available online: http://digital.csic.es/dc/memoria-digital-csic/ (accessed on 24 April 2019).

8. INEOS Project. Available online: https://www.fecyt.es/es/tematica/ineos-ciencia-en-abierto (accessed on 24 April 2019).

9. Ayris, P.; Bernal, I.; Cavalli, V.; Dorch, B.; Frey, J.; Hallik, M.; Hormia-Poutanen, K.; Labastida, I.; MacColl, J.; Ponsati Obiols, A.; et al. LIBER Open Science Roadmap. 2018. Available online: https://zenodo.org/record/1303002 (accessed on 24 April 2019).

10. López, I.; Ponsati Obiols, A.; Baquero Arribas, M. Spanish Participation in SCOAP3: Making Open Access Possible to Scientific Publications in the area of Particle Physics. 2015. Available online: https://digital.csic.es/handle/10261/134993 (accessed on 24 April 2019).

11. Gumpenberger, C.; Hölbling, L.; Gorraiz, J.I. On the Issues of a "Corresponding Author" Field-Based Monitoring Approach for Gold Open Access Publications and Derivative Cost Calculations. Front. Res. Metr. Anal. 2018, 3, 1. [CrossRef]

12. The INTACT Project Offers Information that can be Parameterized by Publishers, Years or Institutions. The Results in These Cases are Higher. INTACT Records a Mean Value APC of $€ 2000$ in 2017. Available online: https://www.intact-project.org/openapc/ (accessed on 24 April 2019).

13. CSIC Open Access Publishing Support Fund Dedicated Page. Available online: http://bibliotecas.csic.es/ publicacion-en-acceso-abierto (accessed on 24 April 2019).

14. Pinhasi, R.; Blechl, G.; Kromp, B.; Bernhard, S. The Weakest Link-Workflows in Open Access Agreements: The Experience of the Vienna University Library and Recommendations for Future Negotiations. Insights 2018, 31, 27. [CrossRef]

15. Díaz-Faes, A.A.; Bordons, M.; van Leeuwen, T.N. Integrating metrics to measure research performance in social sciences and humanities: The case of the Spanish CSIC. Res. Eval. 2018, 25, 451-460. [CrossRef] 
16. The Open Access Citation Advantage Service. Available online: https://sparceurope.org/what-we-do/openaccess/sparc-europe-open-access-resources/open-access-citation-advantage-service-oaca/oaca-list/ (accessed on 24 April 2019).

17. Nature Communications Journal Report 2014. Available online: https://www.nature.com/press_releases/ ncomms-report2014.pdf (accessed on 24 April 2019).

18. There is an informal working group in Spain for several years (Spanish national board of consortia) which meets virtually twice a month, and face-to-face meetings whenever possible- composed by the directors of all national consortiums of university libraries, purchasing groups of university libraries and CSIC. It is a forum in which all concerns about negotiations with scientific publishers are brought together, and where possible, national-level agreements that benefit everyone. The financial and technical management of any agreement reached corresponds separately to each institution, since there are not any national consortia in Spain like JISC, VSNU or Couperin.

19. REBIUN Statistics. Available online: https://rebiun.um.es/rebiun/admin/ManageIndicatorsPage (accessed on 24 April 2019).

20. INTACT Project. Nature Communications APC. Available online: https://treemaps.intact-project.org/apcdata/ openapc/\#journal/Nature\%20Communications/period=2017 (accessed on 24 April 2019).

21. INTACT Project. Scientific Reports. Available online: https://treemaps.intact-project.org/apcdata/openapc/ \#journal/Scientific\%20Reports/period=2017 (accessed on 24 April 2019).

22. Pieper, D. OpenAPC — transparent reporting on article processing charges reveals the relative costs of open access publishing. LSE Impact Blog. Available online: https://blogs.lse.ac.uk/impactofsocialsciences/2018/ 10/25/openapc-transparent-reporting-on-article-processing-charges-reveals-the-costs-of-open-accesspublishing/ (accessed on 29 October 2018).

23. INTACT Project. Median APCs for Hybrid Journals. Available online: https://reemaps.intact-project.org/ apcdata/openapc/\#publisher/period=2017\&is_hybrid (accessed on 24 April 2019).

24. SELL Thesaloniki Declaration. Available online: https://www.heal-link.gr/SELL/wp-content/ uplOpenAccessds/2018/06/SELL_Thessaloniki_statement_may_2018.pdf (accessed on 24 April 2019).

25. FECYT Hacia Un Acceso Abierto Por Defecto (Towards an Open Access per default). Available online: https: //recolecta.fecyt.es/sites/default/files/contenido/documentos/OPENACCESS_PorDefecto.pdf (accessed on 24 April 2019).

26. Spanish Consortium Launches Groundbreaking Read \& Publish Agreement. Available online: https: //www.rsc.org/news-events/articles/2019/feb/read--publish-csic/ (accessed on 18 June 2019).

27. ESAC Agreement Registry. Available online: https:/esac-initiative.org/about/transformative-agreements/ agreement-registry/ (accessed on 18 June 2019). 